\title{
A deep geoelectric survey of the Carnmenellis granite
}

\author{
David Beamish
}

British Geological Survey, Murchison House, West Mains Road, Edinburgh EH9 3LA, UK

Beamish, D., 1990. A deep geoelectric survey of the Carnmenellis granite. Geophysical Journal International, 102, 679-693.

DOI: $10.1111 / j .1365-246 X .1990 . t b 04589 . x$

Key words: geoelectric, geothermal, granite, Hot Dry Rock, magnetotelluric.

\section{SUMMARY}

A magnetotelluric survey across the Carnmenellis granite, part of the Cornubian batholith of SW England, is described. The granite is being investigated with reference to the extraction of Hot Dry Rock geothermal energy. The sounding data are found to be influenced by near-surface static distortion which can be minimized by the construction of a granite-average sounding tensor. The anisotropy in the average tensor can be attributed to the spatial form of the granite. This is verified by 2-D modelling and the model results are used as control in the assessment of the vertical resistivity profile. The resistivity values obtained by the survey are found to correspond to a saturated 'wet' granite down to at least $10 \mathrm{~km}$. Despite the high geothermal gradient the anticipated decrease of resistivity with increasing temperature does not take place. Below a depth of just over $1 \mathrm{~km}$, resistivity values are found to increase to a depth of about $6 \mathrm{~km}$. The results are compared with the laboratory-observed response of granite to increasing applied pressure and stress. The resistivity/depth section appears consistent with the completion of joint and crack closure by a depth of $7 \mathrm{~km}$ and a transfer to a pore-dominated resistivity mechanism below this depth. An electrical base to the granite is resolved at a depth of $14 \mathrm{~km}$ in accord with the depth to base adopted by regional gravity models. 


\section{INTRODUCTION}

This report considers the results of a field magnetotelluric (MT) survey carried out across the Carnmenellis granite in SW England. The Carnmenellis granite (CG in the location map of Fig. 1) is one of a series of outcropping plutons that occur within the late Carboniferous (Variscan) orogenic belt of Cornwall and Devon. Together the granite plutons make up the Cornubian batholith of SW England. The ridge of granite extends to mid-crustal depths and is some $200 \mathrm{~km}$ in length. A development site for the extraction of Hot Dry Rock (HDR) geothermal energy is located on the Carnmenellis granite (Rosemanowes quarry, RQ in Fig. 1). The geotechnical requirements of HDR exploitation (e.g. Batchelor 1984) require assessments of rock/fluid properties down to depths of at least $6 \mathrm{~km}$ where temperatures are predicted to be in excess of $200^{\circ} \mathrm{C}$ (Anon. 1987). This depth range is immediately accessible using the frequency bandwidth of present-day MT sounding equipment. Results relating to the internal resistivity structure of the granite and its base are presented and discussed.

Established compilations of representative resistivity values of crystalline, and in particular granitic, rocks suggest very high values in excess of $10000 \mathrm{Q} \mathrm{m}$ (e.g. Telford et al. 1976). While such values may be representative of 'intact' crystalline rock they are not in accord with the results of the present survey which provides values of several thousand $Q m$ for the entire granite section. In such circumstances the Carnmenellis granite must be viewed as comprising very resistive 'intact' rock and many voids such as joints, cracks and pores which are saturated with interstitial fluids. Both the flow of fluid (governed by the permeability of the rock) and the flow of electric current (governed by the resistivity of the rock) are then principally controlled by the nature of the void and fluid content (Walsh \& Brace 1984). The applicability of the 'Brace' model appears to be confirmed by an examination of the resistivity laterologs from the geothermal wells at Rosemanowes quarry (supplied by the Camborne School of Mines). The deepest well (RH15), logged to a depth of $2.8 \mathrm{~km}$, reveals intact formation resistivities of the order of the tool limit (200000 Q m) but with a considerable depth-integrated density of fracture resistivities descending to several thousand, and in some cases, to several hundred $\mathrm{Q} \mathrm{m}$. The bulk resistivity in such circumstances will be controlled by the low-resistivity fluid content of fractures and pores within the resistive intact matrix. Granite-water interactions in the Carnmenellis granite have been considered by Burgess et al. (1982) and by Edmunds et al. (1988). Mining operations in Cornwall have encountered high-salinity groundwaters within the granite and adjacent rocks. These waters have a salinity of up to $30 \mathrm{~g} / \mathrm{l}$. The present thermal waters (up to $55^{\circ} \mathrm{C}$ ) probably represent active circulation cells (in the upper kilometer) composed of recent descending meteoric waters and older saline water circulating very slowly in the granite. The results imply that fracture permeability is an important feature of the granite. It is considered likely that the natural groundwater at depths of 6-7 km will have a salinity in excess of $30 \mathrm{~g} / \mathrm{l}$ (Edmunds et al. 1988).

The regional geometry of the batholith has been examined by gravity modelling (WillisRichards 1986; Sams \& Thomas-Betts 1988). These studies, combined with a few conclusions that can be drawn from seismic experiments, support the idea of the granite being homogeneous down to a fiat base. The base of the granite has been estimated at between 10 and $15 \mathrm{~km}$ from seismic refraction studies (Brooks, Doody \& Al-Rawi 1984) and at 14-15 km from 3-D gravity modelling (Willis-Richards 1986). The wide- angle seismic refraction results of Brooks et al. (1984) suggest an acoustic interface (R1) in the depth range $7-8 \mathrm{~km}$. Survey line 4 crossing the Carnmenellis granite observed two reflectors (R1, R2) above the Moho. The shallow reflector (R1) appeared to be confined to the granite. The model reflector R1 defines the upper surface of a low-velocity zone which extends to the second reflector (R2) in the depth interval 12 to $15 \mathrm{~km}$. In contrast to the seismic refraction results, no internal features were imaged by two regional normal incidence 
seismic reflection surveys crossing the Carnmenellis structure (Camborne School of Mines Geothermal Energy Project 1989).

Two influences on the electrical properties of granite that must be considered are temperature and pressure. The Cornubian batholith is characterized by the highest measured heat flow values in the UK. The heat flow field and subsurface temperatures for the Carnmenellis granite are discussed by Wheildon \& Rollin (1986), Lee (1986) and by Sams \& Thomas-Betts (1988). The predicted sub-surface temperature profile for the Carnmenellis granite provides a temperature of $200^{\circ} \mathrm{C}$ at about $5.4 \mathrm{~km}$ and indicates a temperature of $370 \mathrm{deg} C$ at a depth of $10 \mathrm{~km}$. On the basis of the Brace model, the effect of temperature in a saturated granite is usually incorporated by using the known variation of the pore fluid resistivity with temperature (Lee, Vine \& Ross 1983). The empirically determined expression relating fluid resistivity to temperature depends on a set of electrolyte-dependent coefficients (Quist \& Marshall 1968). If the pore fluid has a salinity close to seawater then the fluid resistivity $\left(\rho_{\mathrm{f}}\right)$ depends on temperature as:

$\rho_{f}=(3+T / 10)^{-1}$

(Becker et al. 1982) where $\mathrm{T}$ is the temperature in deg C. The relationship is approximately valid up to $300^{\circ} \mathrm{C}$. If the predicted temperature profile for the Carnmenellis granite is used in this expression, the result indicates a factor of 10 decrease in the component of bulk resistivity determined by the fluid phase over the upper $10 \mathrm{~km}$ of the crustal section. The Brace model and the theory of pressuredependent resistivity in low-porosity rocks, saturated with different pore fluids, was established by Brace and co-workers (Brace, Orange \& Madden 1965; Brace, Padding \& Scholz 1966; Brace, Walsh \& Frangos 1968). Specifically, the experiments showed that as the external confining pressure is increased, the resistivity rises sharply and then less so.

The dilatancy of the samples as a function of pressure was also measured. The dilatancy rises sharply with pressure and then asymptotically approaches a straight line. The conclusion was that some of the porosity (called cracks) closes up quickly with pressure while that remaining (called pores) does not. This qualitative picture has since been verified by many other experiments on similar systems. It is important to point out that the definition of 'cracks' and 'pores' (as discussed in the above papers) is in terms of their response to pressure or stress. Thus 'cracks' close under applied pressure while 'pores', though free to deform elastically, remain open. Due to the fact that the experiments indicate that a wide range of rock types display this type of behaviour, it is presumed that nearly all rocks must contain high-aspect ratio void spaces that can be closed by applied pressure. The laboratory observations provide further evidence that pore space remains connected in most rocks in spite of deep burial. For example, Brace \& Orange (1968) report that an effective pressure of $1000 \mathrm{MPa}$ was insufficient to eliminate water-filled pore spaces in granitic and other rocks.

For a realistic granite mass, and the Carnmenellis granite in particular, the pressure dependence should take into account the likely influence of both the jointed nature of the granite and the in situ, highly deviatoric stress distribution. The joint/fracture types of the Carnmenellis granite have been discussed by a number of authors. According to Heath (1985) and Green, Baria \& Jones (1987), two groups of principal joint sets are observed at the surface. A further feature of the Carnmenellis granite is the anisotropic nature of the horizontal stress field at depth (Green et al. 1987). Such pressure/stress effects are discussed in more detail following a description of the field survey and the results obtained. 


\section{THE FIELD SURVEY}

The MT survey was undertaken in 1988 using an in-house field system. The computer-based system collects and analyses seven channels of natural electromagnetic fields across a frequency range from 100 to $0.01 \mathrm{~Hz}$. The system provides a composite bandwidth using four decade ranges. The seven channels of data are two local electric fields, three local magnetic fields and two reference magnetic fields. The two reference magnetic sensors were used in a local reference mode and this proved satisfactory. The approximate separation between local and remote sensors was $200 \mathrm{~m}$. The main sources of noise were localized ground-coupled electric field transients derived from agricultural electric fences. True remote reference operation would not have been advantageous in the circumstances encountered.

The methods of in-field data processing are not described here. The main elements of frequencydomain tensor estimation are based on the established procedures of remote-reference techniques described by Gamble, Goubau \& Clarke (1979) and by Travassos \& Beamish (1988). Figure 1 shows the sounding locations in relation to the outcrop of the Carnmenellis granite. The main E-W profile (solid dots) consisted of 12 sites at a spacing of approximately $1 \mathrm{~km}$. The site numbers of the profile sites are denoted as 101 (western-most) through to 112 (eastern-most) and increase easterly.

\begin{tabular}{|c|c|c|c|}
\hline SITE & EASTING & NORTHING & ELEVATION \\
\hline 101 & 663 & 322 & 150 \\
\hline 102 & 680 & 320 & 140 \\
\hline 103 & 685 & 325 & 125 \\
\hline 104 & 689 & 313 & 173 \\
\hline 105 & 694 & 327 & 125 \\
\hline 106 & 708 & 320 & 140 \\
\hline 107 & 716 & 320 & 185 \\
\hline 108 & 716 & 323 & 182 \\
\hline 109 & 724 & 303 & 145 \\
\hline 110 & 742 & 323 & 175 \\
\hline 111 & 753 & 325 & 145 \\
\hline 112 & 764 & 322 & 100 \\
\hline 201 & 625 & 306 & 97 \\
\hline 202 & 716 & 276 & 70 \\
\hline
\end{tabular}

This set of locations, forming an approximately E-W profile confined to the granite outcrop, form the basis of the present study. Site 108 did not provide results of sufficient quality to be included in the present analysis. The results presented are based on the remaining 11 sounding locations. Two soundings (sites 201 and 202, Fig. 1) were obtained off the outcrop primarily for dimensional and spatial control. Three further soundings were undertaken in the vicinity of the present geothermal reservoir at Rosemanowes quarry. The results obtained at these locations are not discussed here since two of the locations are influenced by the artificial permeability of the geothermal reservoir (Beamish \& Riddick 1989). Grid coordinates for the sounding locations considered here are provided in Table 1.

\section{RESULTS OF THE SURVEY}

Magnetotelluric sounding curves in the off-diagonal(measured) directions are shown for two 
representative sites (102 in the west and 111 in the east) in Fig. 2. Resultsrelating to the off-diagonal elements of the impedancetensor will be referred to as $X$ (derived from impedanceelement $Z x y$ ) relating to the geomagnetic north direction and $Y$ (derived from impedance element $Z y x$ )re lating to the geomagnetic east direction. Data quality, as indicated by the standard errors in Fig. 2, generally decreases from high tolow frequencies. There are several characteristics in the example results that are observed at all sites on the granite outcrop. The sounding curves in the $X$ direction display a consistent increase with decreasing frequency whereas the sounding curves in the $Y$ direction display only a slightgradient. The anisotropy ratio increases with decreasingfrequency and a transition occurs at about $10 \mathrm{~Hz}$ to establishthe apparent resistivity in the $\mathrm{X}$ direction as the larger of the two sounding curves. A significant phase difference exists between the two sounding directions.

The observed data characteristics indicate that the results both on and off the granite cannot be simply interpreted in terms of 1-D vertical resistivity structure. In order toprovide reasonable interpretations of the data, anassessment of the likely dimensional influences on the tensor data was performed. A background to the assessments considered here is given by Beamish (1986). The skew values for the data were examined to identify likely 3-D contributions to the sounding data. Sites on the granite outcrop are characterized by skew values of $<0.2$ except at the very lowest frequencies. The off-granite site 202 appears to be the only site influenced by a significant3-D contribution. To further investigate dimensional influences, the dimensional weights $D I, D 2$ and $D J$ (see Beamish 1986) were examined. The 1-D (D1) weights are high (>0.75) for sites on the granite outcrop and display only a slight decrease with decreasing frequency. The 2-D (D2) weights for these same sites are of the order of 0.1 and are consistent across the granite. The two off-granite sites provide very different dimensional characteristics to sites on the granite. The 1-D weight at site 201 is low and the 2-D weight is high suggesting a significant 2-D contribution at this off-granite site. The 3-D (D3) weight at site 202 is high and frequency dependent. The result confirms the high skew value and emphasizes the 3-D influence at this off-granite site. The conventional dimensionality indicators indicate that, apart from the very lowest frequencies, the sounding data on the granite possess a strong 1-D contribution while retaining an additional and spatially persistent 2-D influence. The data obtained at the two off-granite locations appear to be influenced by much more complex dimensional contributions and are not discussed further here.

\section{SPATIAL CHARACTERISTICS}

If measured MT data are influenced by near-surface resistivity contrasts which cannot be resolved by the instrumental bandwidth they nevertheless influence the measured fields and will remain 'unresolved' by any form of modelling. In such circumstances the conventional dimensionality indicators considered above do not provide a complete description of the influences on the MT tensor (Groom \& Bailey 1989). Any near-surface feature 'unresolved' in a vertical sense may still be detected by its lateral influences on the measured fields (unless it is 1-D). Such lateral detection is obviously a function of sounding location and recent schemes to suppress the influence of nearsurface resistivity contrasts involve the use of 'continuous' MT profile measurements (Bostick 1986; Shoemaker, Shoham \& Hockey 1989). With conventional (discrete) MT soundings a reasonable approach is to examine the lateral or spatial behaviour of the sounding curves obtained.

MT sounding curves along a profile can be conveniently plotted as pseudo-sections with decreasing frequency (logarithmic scale) representing a form of increasing penetration depth. The tensor nature of MT data may sounding curve or the reduction of the tensor to a representative scalar and rotationally invariant sounding curve. The two most common reductions are referred to as the average (or effective) and determinant invariant response curves (Berdichevsky \& Dmitriev 1976). Ranganayaki (1984) has shown that the apparent resistivity and particularly the phase pseudo- 
sections obtained from the determinant invariant can provide useful 'direct' assessments of the resistivity structure. The use of invariant response curves for 1-D assessments of structure has been considered in a number of theoretical modelling studies (Ingham 1988; Park \& Livelybrooks 1989). These studies essentially relate to the use of one or other invariant response curves determined at individual sounding locations in an attempt to 'suppress' the influence of near-surface 3-D resistivity contrasts.

Following the interpretative analysis of Ranganayaki (1984), apparent resistivity and phase pseudosections were constructed using the determinant average obtained at the 11 sounding locations on the granite. The results using the first three decades of the sounding bandwidth are shown in Fig. 3 . The maximum depth of penetration is of the order of $15-20 \mathrm{~km}$. The presentation summarizes the overall features of the sounding data in sectional form across the granite outcrop. Although the apparent resistivity values possess a limited range (predominantly 1000-5000 $\Omega \mathrm{m}$ ) there is a clear indication of vertical zoning while the phase values possess a horizontally stable pattern. Such conflicting 'patterns' are now considered by many to be a manifestation of near-surface static distortion effects. The results shown in Fig. 3 suggest that the invariant response may not be effective in 'suppressing' near-surface effects and the data need to be examined in more detail as discussed below.

\section{STATIC DISTORTION}

The influences of near-surface distortion on MT data are receiving growing attention in the literature (e.g. Jones 1988; Sternberg, Washburne \& Pellerin 1988) and have been termed galvanic distortion (Berdichevsky \& Dmitriev 1976), static distortion and static shift. The physical cause of the distortion is considered to be the quasi-static electric charge distribution resulting from induced electric currents in non-uniform near-surface resistivity contrasts. The phenomenon is primarily a distortion of the induced electric field. According to existing models of static distortion (e.g. Larsen 1977), nearsurface static distortion produces a shift of the apparent resistivity curve by the same multiplicative factor at all frequencies such that the shape of the sounding curve is preserved in the normal presentation coordinates (i.e. logarithmic) while the phase remains undistorted. Using this same model, static distortion can be allowed for by introducing a static shift tensor $\mathbf{C}_{\mathbf{i}}$ which is a $2 \times 2$ real, frequency independent tensor which operates on the 'true' (i.e. undistorted) tensor 2, to give the measured tensor $\boldsymbol{Z}_{\boldsymbol{m} i}$ at each sounding location i:

$Z_{\text {mi }}(f)=C_{i} Z_{i}(f)$

where $f$ is the frequency. The problem of static distortion effectively reduces to the correct estimation of the frequency-independent 'site gain' described by the real distortion tensor $\mathrm{Ci}$. It follows from the above discussion that the presence of static shift would generate parallel shifts in the apparent resistivity curves while the phase would remain undistorted. It also follows that assessments of static shift should be undertaken using the sounding data in the measured coordinate frame. A general distortion tensor may operate on the two electric field components individually or in combination and therefore parallel shifts can be examined in the individual tensor elements at a single location and, perhaps more importantly, in the individual tensor elements between sites.

The complete set of on-granite sounding curves in the measured off-diagonal ( $\mathrm{X}$ and $\mathrm{Y}$ ) components are summarized in Fig. 4. Each curve has been interpolated using cubic-splines to allow a better assessment of the degree of parallel behaviour. The sounding data at site 105, which displays the lowest resistivities in both components, is shown dotted. Despite some small-scale irregularities introduced by measurement noise it can be seen that the response characteristics are consistent 
across the granite in apparent resistivity and phase for each of the two components. It can also be noted that there is evidence of parallel shifts in the apparent resistivity curves of the individual components across the granite. The phase curves however provide very similar values in each of the two components. The results shown in Fig. 4 strongly suggest that near surface static distortion operates on both the $X$ and $Y$ component data as a function of location across the granite. The distortion also appears to operate across the entire observational bandwidth (100-0.01 Hz). The fact that there is very little evidence of 'clustering' in the apparent resistivity curves suggests that the static effects observed are not localized (e.g. alluvial-filled depressions) but may be related to the entire cover/granite outcrop relationship which is undoubtedly electrically thin and 3-D.

Both Jones (1988) and Sternberg ef al. (1988) discuss methods of data treatment for conventional (discrete) MT data sets suffering static shift. As previously noted theproblem reduces to the estimation of the distortion tensor or equivalently to the site gain for individual measured components. With no independent measurements to constrain the problem an a priori assumption must be made. It is clear that even with the introduction of independent (e.g. TDEM) measurements of the surface resistivity (Sternberg et al. 1988) the estimation of resistivity structure becomes a statistical problem. Most attempts to treat conventional MT data containing static shift effects involve some form of spatial averaging with some loss of spatial resolution. The essential aim is either to estimate and remove, or simply suppress, the distortion tensor at each site so that the resulting sounding curve possesses an appropriate 'level' (in apparent resistivity) while the shape and original phase data are preserved. As an example, Sternberg, Washburne \& Anderson (1985) determined a site-average apparent resistivity for each site and an area-average apparent resistivity around each site. Theapparent resistivity curve for each site was then shifted by the difference between the two averages. Obviously the removal or suppression of static distortion effects will depend on the data set (e.g. profile or array) and on the magnitudes and frequency bandwidth of the distortion encountered. Many hybrid schemes are thus possible.

The influence of static distortion on the present data set has been summarized in Fig. 4. It can be noted that the influence appears to extend over the four decade frequency range and that individual data components require separate treatment to preserve their separate response characteristics. It is usual to assume that the distortion tensor is a random function of location (e.g. Berdichevsky et al. 1980) and therefore the unknown site gains can be assumed normally distributed. Although the number of data aresmall, the results in Fig. 4 suggest that this is a reasonable approximation. The most effective treatment for the present data set appears to be to form a 'granite-average' impedance tensor at each frequency using all 11 soundings on the granite. This approach sacrifices all lateral resolution across the granite but attempts to establish the most appropriate sounding curve for assessments of vertical structure. The averaging scheme involved all 11 sites on the granite and the real and imaginary parts of each tensor element were treated separately. Although several central moments of the element populations were investigated the arithmetic mean gave comparable and satisfactory results. Standard errors (68 per cent confidence limits) associated with the means were calculated from the variances of the populations using the Student-t distribution.

Figure 5 shows the granite-average sounding curves in the $X$ and $Y$ off-diagonal components together with the determinant average curve obtained from the complete granite-average tensor. Errors have been omitted for the sake of clarity. The two components shown in Fig. 5 clearly retain the frequency characteristics observed in previous data plots. The results shown in Fig. 5 probably represent the 'best-available' sounding curves for assessments of the vertcal resistivity structure of the granite given the nature of the static distortion effects encountered. As noted previously, the use of rotational invariants for 1-D assessments of vertical structure has been considered in a number of studies. These studies usually relate to the use of invariant average response curves at 
individual locations in an attempt to 'suppress' the influence of near-surface resistivity variations. In the case of the present data this approach failed (Fig. 3). The suppression of static distortion involved the formation of the granite-average sounding curves of Fig. 5 . In such circumstances, the formation of the granite-average invariant sounding may still be useful in that it should provide a horizontally averaged scalar resistivity sounding of the regional structure (e.g. Ranganayaki 1984; Groom \& Bailey 1989). The use of the invariant as discussed later should be understood in these terms. The treatment of the data set for static shift has reduced the original profile data to a single granite-average tensor that clearly represents the frequency response characteristics observed across the whole granite (compare Figs 4 and 5). The granite-average tensor can be subjected to the dimensionality assessments discussed previously and verysimilar comments to those made earlier apply again. The problem is to provide a reasonable assessment of the vertical resistivity structure using tensor data that is primarily 1-D but is influenced by a persistent 2-D contribution but in which static distortion effects should have been minimized. The likely causes of the residual 2-D tensor anisotropy were investigated by forward 2-D modelling as discussed below.

\section{2-D MODELLING}

The regional form of the Cornubian batholith has been extensively investigated by 3-D gravity modelling (Wiilis- Richards 1986; Camborne School of Mines Geothermal Energy Project 1989). The granite root underlies the complete peninsular shown in detail in Fig. 1 and the adopted base (for the final gravity model) lies between 14 and $15 \mathrm{~km}$ beneath the Carnmenellis outcrop. The finat regional gravity model provides a 3-D geometrical form for the Carnmenellis structure whose symmetries can be exploited to establish a reasonable approximation to a 2-D profile. The major asymmetries in the spatial form of the Carnmenellis granite occur to the south and east of the outcrop. Although the MT profile ran E-W, both the seismic reflection and refraction profiles had a major N-S component and an initial 2-D model cross-section was constructed in an approximately N$S$ direction as shown in Fig. 6 . It should be noted that a very similar geometrical form to the granite would be formed in an E-W direction by translating north to west and south to east in Fig. 6 . The geometrical form of the granite shown in Fig. 6 has been determined from the final gravity model adopted by the Camborne School of Mines and a uniform base at $14 \mathrm{~km}$ has been used.

Although the off-granite soundings suggest resistivities of 300-400 $\Omega \mathrm{m}$ for the Devonian cover rocks a 'lower-bound' of $100 \Omega \mathrm{m}$ was used as a background resistivity in which to immerse the uniform granite having a resistivity of $1000 \Omega \mathrm{m}$. It should be noted that the 2-D model constructed in Fig. 6 is not intended to fit the data in a precise way. The primary purpose of the model is to investigate the extent to which a 'first-order' 2-D model of the geometrical form of the granite can account for the observed anisotropy. It should be understood that the limited data will provide virtually no constraints in relation to the development and assessment of more complex regional 2-D models. The possible influences due to the coastline and sea water were ignored and it is evident that the applicability of this first-order model will necessarily decrease with decreasing frequency.

2-D model results were generated using the finite-element algorithm of Wannamaker, Stodt \& Rijo (1987) at 13 frequencies between 100 and $0.01 \mathrm{~Hz}$. To simulate the field data, model sounding data were obtained at 11 locations spaced $1 \mathrm{~km}$ apart on the granite outcrop. The bounding locations were situated a distance of $1 \mathrm{~km}$ from the outcrop margins. For the $\mathrm{N}-\mathrm{S}$ profile model, the $\mathrm{E}$ polarization mode of induction provides results which are equivalent to the $Y$ component field data and the $\mathrm{H}$-polarization mode provides results equivalent to the $X$ component field data.

The 2-D model results for the 11 locations across the granite are shown in Fig. 7 as the solid and dotted response curves. Locations on the granite are very little influenced by the lateral response perturbations which occur primarily in the more conductive regions off the granite margins. Spatial 
variability can be seen to be greater in the $\mathrm{X}$ component results (H-polarization).

To enable a direct comparison with the granite-average sounding data the 2-D model results at the 11 locations on the outcrop were processed (averaged) in an analogous manner to those of the field data to provide granite-average model sounding data. The only difference lies in the fact that 2-D models cannot generate diagonal tensor elements so that these must be treated as true zeros in the construction of spatial model averages. The determinantaverage sounding curve for the model was then determined from the granite average tensor. The result is shown by the solid symbols in Fig. 7 . The model results shown in Fig. 7 can be directly compared with the granite average survey data shown in Fig. 5 although, as noted previously, the comparison should possess a greater degree of validity in the higher frequency portion of the bandwidth. It seems very evident that the firstorder model can account for the main anisotropic features in the observed response with a fair degree of accuracy. The main imbalance between the two sets of results occurs with decreasing frequency and clearly the continuation of a uniform conductive background resistivity into the lower crust is not a realistic forward model. The differences which occur in the higher frequency range are due to the non-uniform behaviour of the vertical resistivity profile of the granite as discussed below. The main conclusion from the comparison is that the anisotropy in the observed granite-average sounding data can be directly attributed to the 2-D influence of the geometrical form of the granite.

\section{ASSESSMENT OF THE VERTICAL RESISTIVITY PROFILE}

To enable some controlled assessments to be made concerning the vertical resistivity profile associated with the granite-average sounding data, the equivalent data obtained from the 2-D model were first subjected to 1-D inversion. The performance of all three components $(X, Y$ and determinant average) was considered. The 1-D inverse methods used are an attempt to recover the resistivity profile using automatic methods. A sounding curve and its associated errors are used to provide models that are consistent with the observations at a certain level of misfit. Two inversion schemes have been used. The first scheme provides minimum-norm (best-fit) solutions when the section is characterized by a series of layers. The second scheme provides a solution as a smooth resistivity profile at a chosen level of misfit. The overall misfit between the observations and model is usually described by the chi-square statistic or by the root mean square (rms) error (e.g. Constable, Parker \& Constable 1987). The latter measure of misfit is used here.

The inversion scheme that treats the vertical section as a stack of discrete layers is due to Fischer \& Le Quang (1981). A layered scheme is obviously appropriate to the 'discontinuous' vertical profile of the model granite which consists of a single boundary at a depth of $14 \mathrm{~km}$. It should be noted that the number of layers used in layered inversions may be a critical factor in the construction of the most appropriate vertical section. The correct choice for the number of layers may be monitored using misfit criteria as described by Fischer \& Le Quang (1981). Presumably due to the effects of 2-D 'distortion' two-layer models (two layers plus half-space) were required to provide rms misfits in the range 1-2 for the model sounding data. The results of the layered inversion using both logarithmic and linear depth scales are shown in Fig. 8(a). The 'true' vertical section comprises a uniform resistivity of $1000 \Omega \mathrm{m}$ from 0-14 km above a half-space of $100 \Omega \mathrm{m}$. The inability of the solutions to provide a precise reconstruction of the true vertical profile is due to the 2-D nature of the data but it can be noted that the determinant average $(A)$ solution provides by far the most accurate model. The granite resistivity is well-approximated and the depth of the true interface is over-estimated by $1.5 \mathrm{~km}$. Identical inversion procedures were applied to the granite-average survey data. For these data, three-layer models were required to provide rms misfits in the range 1-2 for the sounding data. The results are shown in Fig. 8(b). The solutions for all three components are characterized by an 
increase in resistivity in the upper crust followed by a decrease in the middle/lower crust. This is in contrast to the uniform granite results of Fig. 8(a). The results of Fig. 8(b) indicate that the granite resistivity profile is non-uniform and the largest gradient of non-uniformity occurs between 3 and 4 $\mathrm{km}$ (as defined by the determinant average solution).

The layered solutions shown in Fig. 8 are intended to provide assessments of the vertical granite properties which can be considered discontinuous. The base of the granite is an obvious candidate. The 2-D control results of Fig. 8(a) indicate that the determinant average will provide a correct value for the resistivity of the granite, an overestimate of the depth to base and an underestimate of the resistivity contrast at the base. The observed determinant average solution of Fig. 8(b) suggests that below the upper crustal of non-uniformity, the resistivity of the granite maintains a constant resistivity of $4300 \Omega \mathrm{m}$ down to an electrical base which is modelled at a depth of $15.5 \mathrm{~km}$. If we allow an overestimate of order $1.5 \mathrm{~km}$, as suggested by the control results of Fig. 8(a), the invariant average solution would estimate the 'true' electrical base at a depth of $14 \mathrm{~km}$. This result may seem contrived; however, it is based on the determinant average obtained from the granite-average tensor obtained from the 11 sounding locations on the granite. Since the base of the granite should be a uniform feature beneath each site it is likely that the spatial averaging of individual tensors has not only minimized static shift but has also minimized measurement noise to produce an increase in the resolution of a horizontally continuous electrical base.

A granite batholith can be viewed as a single lithologic formation and the parametrization of its internal non-uniform resistivity profile in terms a discontinuous layered model may be inappropriate particularly if the internal resistivity structure is responding to the 'vertically continuous' influences of temperature and pressure. For this reason 1-D inverse solutions involving only smooth behaviour have been investigated. The algorithm for generating smooth vertical profiles is the Occam inversion presented by Constable et al. (1987). Rather than fitting the data as well as possible (which maximizes interface-type behaviour), the smoothest model which fits the data to within an expected tolerance is sought. Rather than seek overly smooth models, the smoothest models consistent with the expectation levels of the data ( $r$ s error $=1$ ) have been constructed.

The algorithm ensures the smooth behaviour of the resistivity profile by strictly controlling the behaviour of its first (or second) derivatives (Constable et al. 1987). Under these circumstances 'true' discontinous behaviour cannot be resolved but it can be incorporated into the inversion scheme as an a priori constraint. The constraint allows for discontinuous (interface) behaviour at one or more pre-determined depths. The algorithm will then determine the smoothest 'overall' model consistent with interface behaviour at the pre-defined depths. Following the investigation of layered models it seems appropriate to incorporate the electrical base of the granite at $14 \mathrm{~km}$ as a single pre-determined depth for discontinuous behaviour and to confine smooth behaviour to depths above and below this interface. Due to logarithmic depth sampling restrictions, the interface was modelled at a depth of $14.6 \mathrm{~km}$.

As in the case of the layered analysis, the 2-D model results can be used as a control. Only the inversion results obtained using the determinant average are presented since the $\boldsymbol{X}$ and $Y$ component data display equivalent (though smooth) behaviour to the layered solutions. The two sets of results are shown in Fig. 9 and it should be remembered that for these results the depth of the interface at $14.6 \mathrm{~km}$ is pre-defined but the magnitude of the resistivity contrast is determined by the inversion. The first point to note is that for the 2-D control model data the smooth inversion has not introduced any false gradients into the profile using an rms misfit of unity. To some extent this confirms the solution accuracy that can be expected from the survey data using the same level of misfit. The granite resistivity is well-represented in the solution for the control model and the base resistivity contrast is much more realistic than that of the corresponding layered solution (Fig. 8b, 
solid line). The smooth inversion of the survey data produces a non-uniform upper crustal profile that can be seen to be a continuous average through the single interface model. The smooth solution provides a minimum $(990 \Omega \mathrm{m})$ in the resistivity profile in the depth range $1.1-1.3 \mathrm{~km}$ and a maximum resistivity $(4000 \Omega \mathrm{m})$ in the depth interval from 5.6-6.8 km. Below the attainment of maximum resistivity the profile is almost constant, as suggested by the equivalent layered solution of Fig. 8(b) (solid line), but displays a slight decrease with increasing depth. The depth of the granite base interface is of course fixed in this solution but the 2-D control model suggests that the resistivity contrast at the base may be underestimated by a factor of the order of 2 .

The base resistivity contrast for the survey data shown in Fig. 9 is 1.6 so it can be suggested that the 'true' granite base resistivity contrast is indeed very small and of the order of 3 . Due to the complexity of the problem, likely errors in the estimate of the preferred vertical profile of the granite (solid line in Fig. 9) are extremely difficult to assess. In one sense the profile obviously represents the 'best-available' result but it can also be argued that the assessments made using

The 2-D control model suggest it is an accurate representation of the regional resistivity structure of the Carnmenellis granite. In terms of HDR reservoir engineering, the portion of the profile above $10 \mathrm{~km}$ is of most immediate concern and the interpretation of the non-uniform upper crustal behaviour is considered in the following section. The results relating to the lower crustal and upper mantle section will be discussed elsewhere.

\section{INTERPRETATION}

The two main mechanisms requiring consideration are temperature dependent and pressure dependent resistivity variations. As noted previously the temperature-dependent behaviour of the vertical resistivity profile of the Carnmenellis granite is expected to be a factor of 10 decrease in the component of bulk resistivity determined by the fluid phase over the first $10 \mathrm{~km}$ of the crustal section. The influence of the fluid volume may be described either in terms of rock porosity and degree of saturation (e.g. Brace \& Orange 1968) or by the 'weight per cent' of free fluids (e.g. Olhoeft 1981). According to Olhoeft (1981) the electrical properties of granite appear to be dominantly controlled by the amount of free water in the granite and by temperature. A summary of the temperature dependence of 'wet' and 'dry' granite resistivities presented by Olhoeft (1981) is shown in Fig. 10. Several weight per cent of water may decrease the resistivity by as much as nine orders of magnitude. The resistivity curve for the Carnmenellis granite is also shown. Depth has been converted to temperature using the predicted temperature profile. The highest temperature of $370^{\circ} \mathrm{C}$ corresponds to a depth of $10 \mathrm{~km}$. Two main points arise from the comparisons in Fig. 10.

The first point is that the observed resistivities of the upper crustal section are much closer to the 'granite curve than to the 'dry' curve. This observation accords with the behaviour of the resistivity laterolog for well RH15 at Rosemanowes quarry which was discussed earlier. Clearly the volume, or bulk, resistivity (as determined by the surface soundings) is determined by the low-resistivity fluid content of fractures and pores within the highly resistive intact matrix. The observed vertical resistivity profile indicates that this control is maintained down to at least $10 \mathrm{~km}$. The second point to arise from Fig. 10 is that the laboratory temperature dependence gives rise to a decreasing resistivity with increasing temperature. The vertical resistivity profile requires an increasing resistivity with depth (and temperature). Clearly the temperature effect is offset or modified by a more dominant mechanism within the Carnmenellis granite as discussed below.

As noted previously, the theory of pressure-dependent resistivity in low-porosity rocks, saturated with different pore fluids, was established by Brace and co-workers (Brace et al. 1965, 1966, 1968). 
Their data for the 'typical' response of Westerly granite saturated with $500 \mathrm{~m}$ water are reproduced in Fig. 11. The limitations of such uniaxial laboratory experiments should however be noted. For a realistic granite mass, and the Carnmenellis in particular, we should also take into account the likely influence of both the highly jointed nature of the granite and the in situ anisotropic stress distribution. The deep observations of jointing and stress characteristics within the granite are obviously limited to borehole information. It is known from the Rosemanowes borehole logs that the jointing exists to at least $2.5 \mathrm{~km}$ and we can infer from the microseismicity that it persists to a depth of $4 \mathrm{~km}$. The variation of the magnitude of the stress components has been estimated to a depth of around $2.5 \mathrm{~km}$ (Green et al. 1987). Clearly the borehole observations must be extrapolated to provide deeper information. If all other possible effects are ignored then the linearly extrapolated stress magnitudes at a depth of $6 \mathrm{~km}$ are $180 \mathrm{MPa}$ for the maximum horizontal stress, $150 \mathrm{MPa}$ for the overburden stress and $80 \mathrm{MPa}$ for the minimum horizontal stress.

The fundamental resistivity/pressure dependence of low-porosity granitic rocks has been summarized in Fig. 11. According to these data and all other subsequent experiments the point of inflection between the initial non-linear response and the subsequent high-pressure linear response corresponds to the transfer from crack-dominated behaviour to pore-dominated behaviour. According to Fig. 11, the transition should be complete and all forms of cracks should be closed at pressures of approximately $200 \mathrm{MPa}$. The simple application of the laboratory results to provide a prediction of deep crustal behaviour is however very hazardous given the known anisotropic behaviour of the stress field. The resistivity profile should however respond to all scales (joints and microcracks) and forms of stress dependence within the granite. The observed non-linear increase in the resistivity profile between depths of about 1 and $6 \mathrm{~km}$ appears therefore to have monitored the response of the granite to increasing applied overburden pressure and deviatoric stress. In addition a maximum in the resistivity profile is found in the depth range $5.6-6.8 \mathrm{~km}$. The resistivity profile obtained appears to 'reflect' (i.e. is consistent with) the completion of crack closure at a depth of about $6 \mathrm{~km}$ and a transfer to a pore-dominated resistivity mechanism below this depth. Thus in very simplistic terms, if a joint can be defined as a feature that is capable of 'closing' (and closed here means an inability to support ionic conduction of interstitial fluids) then the above observations suggest the absence of such joints below $7 \mathrm{~km}$.

Of immediate concern to the interpretation of the upper crustal section are the wide-angle seismic reflection results of Brooks el al. (1984) and the two reflectors (R1, R2) discussed previously. The shallowest reflector (R1) was observed at a depth of about 7 to $8 \mathrm{~km}$ and appears to be confined to the granite. The model reflector R1 defines the upper surface of a low-velocity zone which extends to the second reflector (R2) in the depth interval $12-15 \mathrm{~km}$. The interpretations considered by Brooks et al. (1984) were confined to the nature of the horizons rather than the nature of the lowvelocity zone which defines the horizons. The most direct 'interface' comparison is with the minimum norm, layered resistivity profiles of Fig. $8(\mathrm{~b})$. For these solutions it has been argued that the determinant average $(A)$ profile provides the only accurate assessment of vertical structure. On this basis the resistivity profile displays no correspondence with the depth of the R1 reflector. However in the equivalent smooth solution shown in Fig. 9 it can be noted that the depth interval of the low-velocity zone appears to be associated with an interval of approximately constant and maximum resistivity. Thus although no detectable variations in rock/fluid properties can be identified at depths that might be associated with the R1 reflector a correspondence between the low-velocity zone and the depth interval of nearly constant and maximum resistivity has been established.

\section{CONCLUSIONS}

The data obtained across the Carnmenellis outcrop have been examined in some detail in an effort 
to provide a realistic assessment and interpretation of the vertical resistivity structure of the granite. The measured data when examined spatially appear to be influenced by near-surface static distortion. Although the characteristics of the statistical sense, parallel offsets appear to be present in the measured apparent resistivity sounding curves while the phase curves of individual tensor components appear very similar at all locations. If the adopted model of phase-independent static distortion is correct, the horizontally uniform invariant phase values, shown in pseudo-section form in Fig. 3(b), indicate the lateral homogeneity which exists in the resistivity structure across the granite. In order to minimize the influence of static distortion, a granite-average tensor was constructed. Although any spatial average reduces lateral resolution, the resulting average may still be compared to an equivalent average obtained from 2-D and 3-D models in which near-surface resistivity contrasts (i.e. those unresolvable features causing static distortion) have not been incorporated. For the present data the granite-average tensor preserves the frequency characteristics observed across the whole granite.

The resulting tensor represents the 'best-available' sounding data for assessments of the vertical resistivity structure of the granite given the nature of the static distortion encountered. The graniteaverage tensor was found to retain a residual 2-D anisotropy which was investigated by 2-D modelling. It was found that the observed magnitude and form of the tensor anisotropy could be directly attributed to the 2-D influence of the geometrical form of the granite established by regional gravity models. To enable controlled assessments to be made concerning the vertical resistivity profile the observed and modelled granite-average data were both used in 1-D inversion.

Comparisons of the performance of the off-diagonal (directional) and invariant (horizontally averaged) sounding data were undertaken. It was found that the determinant average sounding data provided an accurate assessment of the vertical resistivity structure. The 1-D layered inverse solution is particularly simple. It provides an upper crustal non-uniformity and resolves an electrical base to the granite at an estimated depth of $14 \mathrm{~km}$. It has been suggested that the internal resistivity structure of a granite is better described by a continuous smooth profile. Discontinuous behaviour at the granite base was incorporated into the otherwise smooth solution as an a priori constraint. The model obtained indicates a small resistivity contrast at the granite base (of order 3 ) and a minimum in the resistivity profile in the depth range $1.1-1.3 \mathrm{~km}$. Below this depth, resistivity increases to achieve a maximum $(4000 \Omega \mathrm{m})$ in the depth interval 5.6-6.8 $\mathrm{km}$. In the interpretation of the internal resistivity profile of the granite the likely influences of temperature and pressure have been considered. When laboratory analyses of the thermal dependence of the resistivity of a granite are taken into account, the Carnmenellis formation is found to correspond to a 'wet' granite saturated with several per cent of free water down to at least $10 \mathrm{~km}$. The minimum in the resistivity profile at a depth of just over $1 \mathrm{~km}$ appears to be consistent with the near surface hydrogeological model of the granite described by Burgess et al. (1982). Using chemical geothermometry, these authors suggest that a saline circulation system extends to a depth of 1.1-1.2 km implying the existence of hydraulically significant fractures to the same depth. Below this depth the anticipated decrease of resistivity with increasing depth and temperature is not observed and a more dominant pressure/stress dependence must operate.

Although the laboratory behaviour of pressure-dependent resistivity variations in crystalline rock has been reviewed it is suggested that the results can only be applied in a qualitative manner to a highly jointed granite immersed in an anisotropic stress field. The actual observations of the stress field and its extrapolation with depth require an increasing horizontally deviatoric stress field until it is relieved by viscoelastic creep (Camborne School of Mines Geothermal Energy Project 1989). Using the laboratory experiments of pressure-dependence as qualitative control it is suggested that the increasing upper crustal resistivity profile can be interpreted as the progressive closure of joints and cracks due to increasing applied pressure and stress. The maximum in the resistivity profile in 
the depth range 5.6-6.8 $\mathrm{km}$ is then consistent with the completion of joint and crack closure and a transfer to a pore-dominated resistivity mechanism below this depth interval.

The resistivity profile has been compared with the boundary reflector (R1) of the low-velocity zone modelled by Brooks et al. (1984). Although no equivalent variations in rock/fluid properties are identified in terms of interfaces, a correspondence between the low-velocity zone and the depth interval of nearly constant and maximum resistivity has emerged. These two observations, together with the total absence of reflectors from normal incidence ray paths, are currently being assessed with regard to the nature of the brittle/ductile transition in the depth range 5-7 km (Willis-Richards, J. \& Green, A. S. P., personal communication, 1990).

\section{ACKNOWLEDGMENTS}

It is a pleasure to acknowledge the friendly assistance of the many farmers of the Carnmenellis area who granted land access during the fieldwork. Scott Finnie proved a very capable field assistant and his fortitude is gratefully acknowledged. I thank Marianne Mareschal whose review proved particularly valuable and thanks are due to Steve Constable, Gaston Fischer and Phil Wannamaker for providing algorithm codes. The staff of the Camborne School of Mines, Geothermal Energy Project at Rosemanowes Quarry provided facilities and advice. Their faith in the applicability of the technique is much appreciated. The work described in this report was funded under a contract from the Camborne School of Mines, Geothermal Energy Project (Department of Energy). This report is published with the approval of the Director, British Geological Survey (NERC).

\section{REFERENCES}

Anon., 1987. Hot Dry Rock potential of the United Kingdom, Invest. Geotherm. Potent. UK, British Geological Survey.

Batchelor, A. S., 1984. Hot dry rock geothermal exploitation in the United Kingdon, Mod. Geol., 9, 141.

Beamish, D., 1986. Geoelectric structural dimensions: methods of estimation, old and new, Geophysics, 51, 1298-1309.

Beamish, D. \& Riddick, J. C., 1989. An audiomagnetotellurics survey of the Carnmenellis granite, Technical Report, WM/89/15, British Geological Survey.

Becker, K., Von Herzen, R. P., Francis, T. J. G., Anderson, R. N., Honnorez, H., Laverne, C., Mottl, M. J. \& Newmark, R. L., 1982. In situ electrical resistivity and bulk porosity of the oceanic crust Costa Rica Rift, Nature, 300, 594-598.

Berdichevsky, M. N. \& Dmitriev, V. I., 1976. Basic principles of interpretation of magnetotelluric sounding curves, in KAPG Geophys. Monogr., Geoelectric and Geothermal Studies, pp. 165-221, ed. Adam, A, Akademiai Kiado, Budapest.

Berdichevsky, M. N., Vanyan, L. L., Kuznetsov, V. A., Levandy, V. T., Mandelbaum, M. M., Nechaeve, G. P., Okulessky, B. A., Shilovsky, P. P. \& Shapk, I. P., 1980. Geoelectric model of the Baikal region, Phys. Earth planet. Inter., 22, 1-11.

Bostick, F. X., 1986. Electromagnetic array profiling, 56rh Annual Meeting, SEG, Expanded Abstracts, pp. 60-61, Houston. 
Brace, W. F., Orange, A. S. \& Madden, T. R., 1965. The effect of pressure on the electrical resistivity of water-saturated crystalline rocks, J. geophys. Res., 70, 5669-5678.

Brace, W. F., Padding, B. W. \& Scholz, C., 1966. Dilatancy in the fracture of crystalline rocks, J. geophys. Res., 71, 3939-3953.

Brace, W. F. \& Orange, A. S., 1968. Further studies of the effect of pressure on electrical resistivity of rocks, J. geophys. Res., 73, 5407-5420.

Brace, W. F., Walsh, J. B. \& Frangos, W. T., 1968. Permeability of granite under high pressure, I. geophys. Res., 73, 2225-2236.

Brooks, M., Doody, J. J. \& Al-Rawi, F. R. J., 1984. Major crustal reflectors beneath SW England, 1. geol. SOC. Lond., 141,

Burgess, W. G., Edmunds, W. M., Andrews, J. N., Kay, R. L. F. \& Lee, D. J., 1982. The origin and circulation of groundwater in the Carnmenellis granite: the hydrogeochemical evidence, Invest. Geotherm. Potent. UK, British Geological Survey.

Camborne School of Mines Geothermal Energy Project, 1989. 2C-7 Resource evaluation: overview, ETSU Report No. G137-P14A, pp. 71.

Constable, S. C., Parker, R. L. \& Constable, C. G., 1987. Occam's inversion: A practical algorithm for generating smooth models from electromagnetic sounding data, Geophysics, 52, 289-300.

Edmunds, W. M., Andrews, J. N., Bromley, A. V., Kay, R. L. F., Milodowski, A., Savage, D. \& Thomas, L. J., 1988. Granite-water interactions in relation to Hot Dry Rock geothermal development, Invest.

Geotherm. Potent. UK, British Geological Survey.

Fischer, G. \& Le Quang, B. V., 1981. Topography and minimisation of the standard deviation in onedimensional magnetotelluric modelling, Geophys. J. R. astr. Soc., 67, 257-278.

Gamble, T. D., Goubau, W. M. \& Clarke, J., 1979. Error analysis for remote reference magnetotellurics, Geophysics, 44, 959-968.

Green, A. S. P., Baria, R. \& Jones, R., 1987. Fault-plane analysis of microseismicity induced by fluid injections into granite, in Engineering Geology of Underground Movements, eds Bell, F.

G. \& Cripps, J. C., Proc. 23rd Ann. Conf. Engineering Group Geol. SOC., Nottingham University.

Groom, R. W. \& Bailey, R. C., 1989. Decomposition of magnetotelluric impedance tensors in the presence of local three-dimensional galvanic distortion, J. geophys. Res., 94, 1913-1925.

Heath, M. J., 1985. Geological control of fracture permeability in the Carnmenellis granite, Cornwall: implications for radionuclide migration, Mineral. Mag., 49, 233-244.

Ingham, M. R., 1988. The use of invariant impedances in magnetotelluric interpretation, Geophys. J., 92, 165-169.

Jones, A. G., 1988. Static shift of magnetotelluric data and its removal in a sedimentary basin environment, Geophysics, 53, 967-978. 
Larsen, J. C., 1977. Removal of local surface conductivity effects from low frequency mantle response curves, Acta Geodaet, Geophys. et Montanist., Acad. Sci. Hung., 12, 183-186.

Lee, M. K., 1986. Hot Dry Rock, in Geothermal Energy-the Potential of the United Kingdom, pp. 2141, eds Downing, R. A. \& Gray, D. A., HMSO, London.

Lee, C. D., Vine, F. J. \& Ross, R. G., 1983. Electrical conductivity models for the continental crust based on laboratory measurements on high-grade metamorphic rocks, Geophys. J. R. astr. Soc., 72, 353-371.

Olhoeft, G. R., 1981. Electrical properties of granite with implications for the lower crust, J. geophys. Res., 86, 931-936.

Park, S. K. \& Livelybrooks, D. W., 1989. Quantitative interpretation of rotationally invariant parameters in magnetotellurics, Geophysics, 54, 1483-1490.

Quist, A. S. \& Marshall, W. L., 1968. Electrical conductances of aqueous sodium chloride solutions from 0 to $800 \mathrm{deg}$. and at pressures to 4000 bars, J. Phys. Chem., 73, 978-985.

Ranganayaki, R. P., 1984. An interpretive analysis of magnetotelluric data, Geophysics, 49, 17301748.

Sams, M. S. \& Thomas-Betts, A., 1988. 3-D numerical modelling of the conductive heat flow of SW England, Geophys. J., 92, 323-334.

Shoemaker, C. L., Shoharn, Y. \& Hockey, R. L., 1989. Calibration case study of natural source electromagnetic array data recorded over a well in Oregon, Proc. IEEE, 77, 334-337.

Sternberg, B. K., Washburne, J. C. \& Anderson, R. G., 1985. Investigation of MT static shift correction methods, 55 $^{\text {th }}$ Annual Meeting, SEG, Expanded Abstracts, pp. 264-267, Washington.

Sternberg, B. K., Washburne, J. C. \& Pellerin, L., 1988. Correction for the static shift in magnetotellurics using transient electromagnetic soundings, Geophysics, 53, 1459-1468.

Telford, W. M., Geldart, L. P., Sheriff, R. E. \& Keys, D. A,, 1976. Applied Geophysics, Cambridge University Press, Cambridge, UK.

Travassos, J. M. \& Beamish, D., 1988. Magnetotelluric data processing-a case study, Geophys. J., 93, 377-391.

Walsh, J. B. \& Brace, W. F., 1984. The effect of pressure on porosity and the transport properties of rock, J. geophys. Res., 9425-9431.

Wannamaker, P. E., Stodt, J. A. \& Rijo, L., 1987. A stable finite element solution for two-dimensional magnetotelluric modelling, Geophys. J. R. astr. Soc., 88, 277-296.

Wheildon, J. \& Rollin, K. E., 1986. Heat flow, in Geothermal Energy-the Potential of the United Kingdon, pp. 8-20, eds Downing, R. A. \& Gray, D. A., HMSO, London.

Willis-Richards, J., 1986. Three-dimensional modelling from gravity of the Carnmenellis pluton, West Cornwall, Geophys. J. R. astr. Soc., 74, 251 (Abstract). 


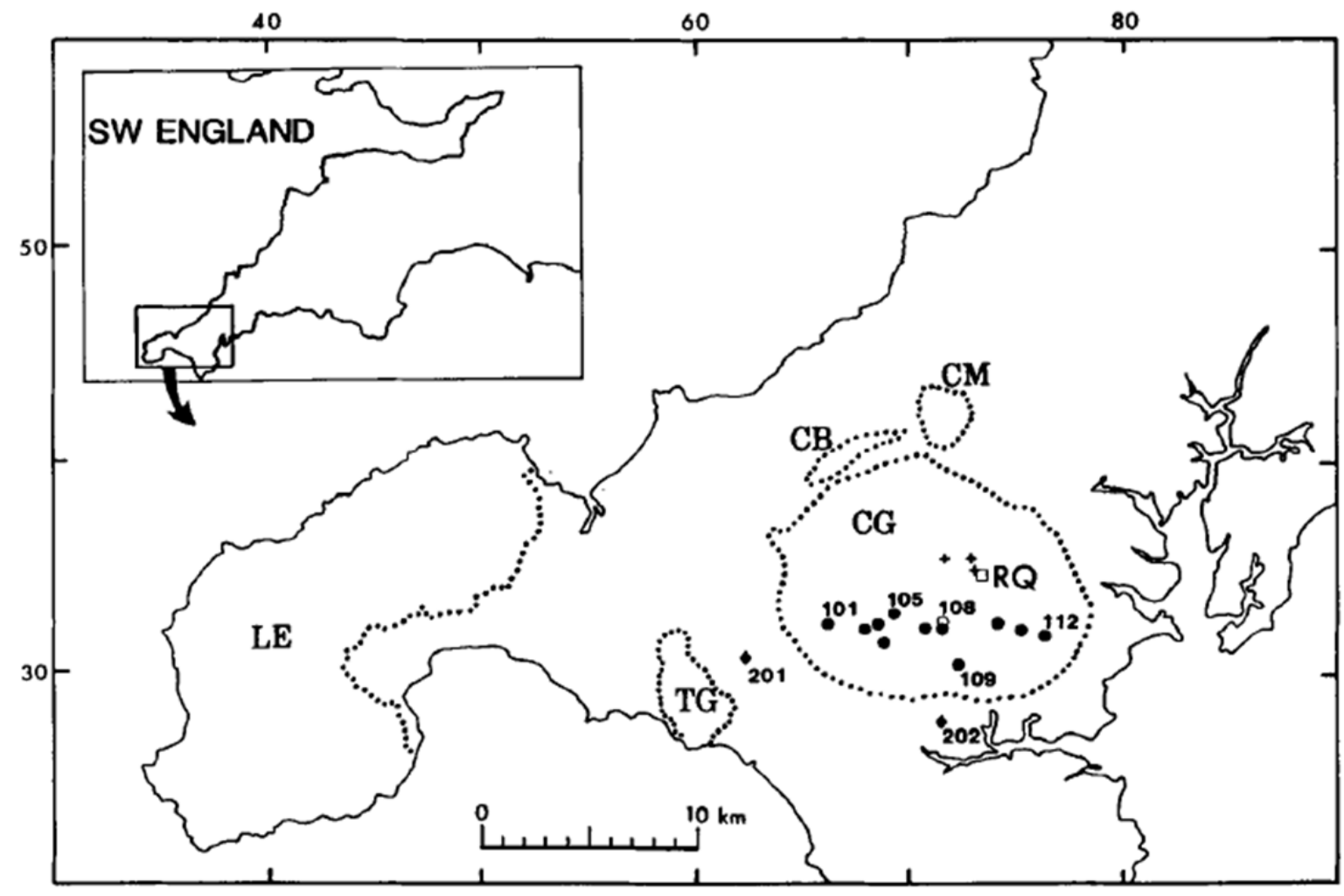

Figure 1. Survey location map. Granite outcrop boundaries are shown dotted. $C G=$ Cammenellis granite, $\mathrm{LE}=$ Land's End granite, $\mathrm{TG}=$ Tregonning-Godolphin outcrop, $\mathrm{CB}=\mathrm{Cam}$ Brea outcrop, $\mathrm{CM}=$ Carn Marth outcrop. On-granite survey sites (101 to 112, site numbers increasing easterly) are shown as solid circles except site 108 (open circle) not used here. Off-granite sites $\mathbf{2 0 1}$ and $\mathbf{2 0 2}$ are shown as diamonds. The location of the HDR test site at Rosemanowes quarry is RQ (open square). 

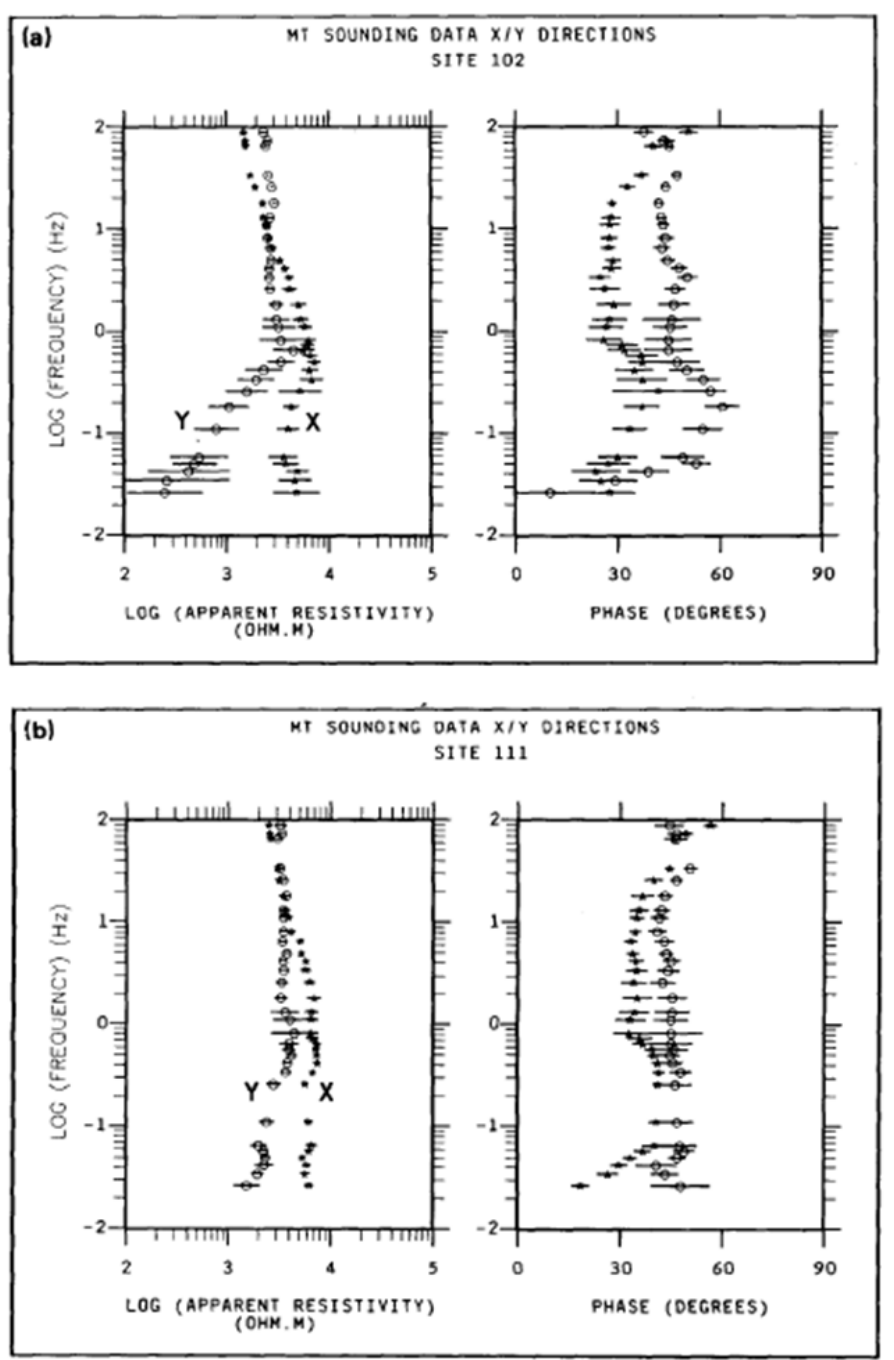

Figure 2. Sounding curves in the measured off-diagonal directions. $\boldsymbol{X}$ is the north component (derived from impedance element $Z \mathbf{X x}$ ), $\boldsymbol{Y}$ is the east component (derived from impedance element Zyx). The error bars are one standard error and in some cases are smaller than the symbol. (a) Location 102. (b) Location 111. 

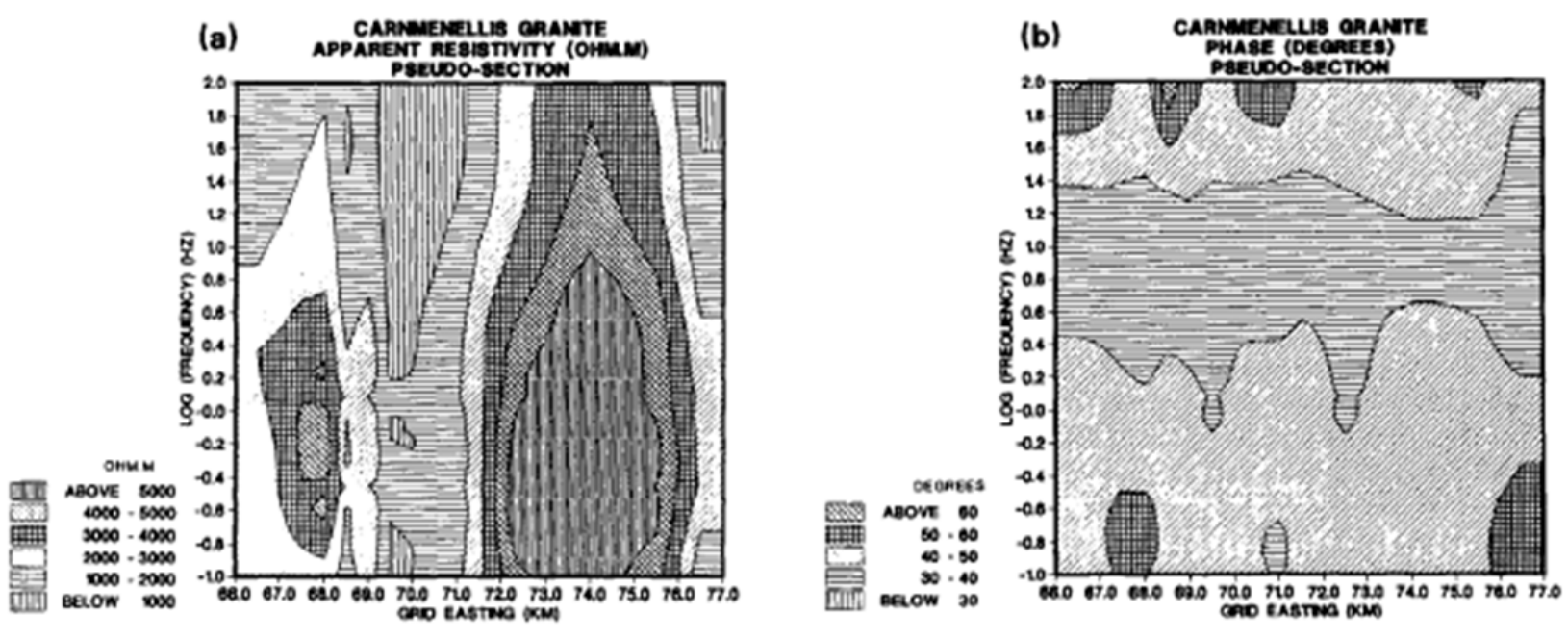

Figure 3. East-west pseudo-sections obtained from the determinant average invariant at the 11 sounding locations on the granite outcrop. First three decades of the sounding bandwidth. (a) Apparent resistivity in $\Omega \mathrm{m}$, contour interval $1000 \Omega \mathrm{m}$. (b) Phase in degrees, contour interval 10 deg. 

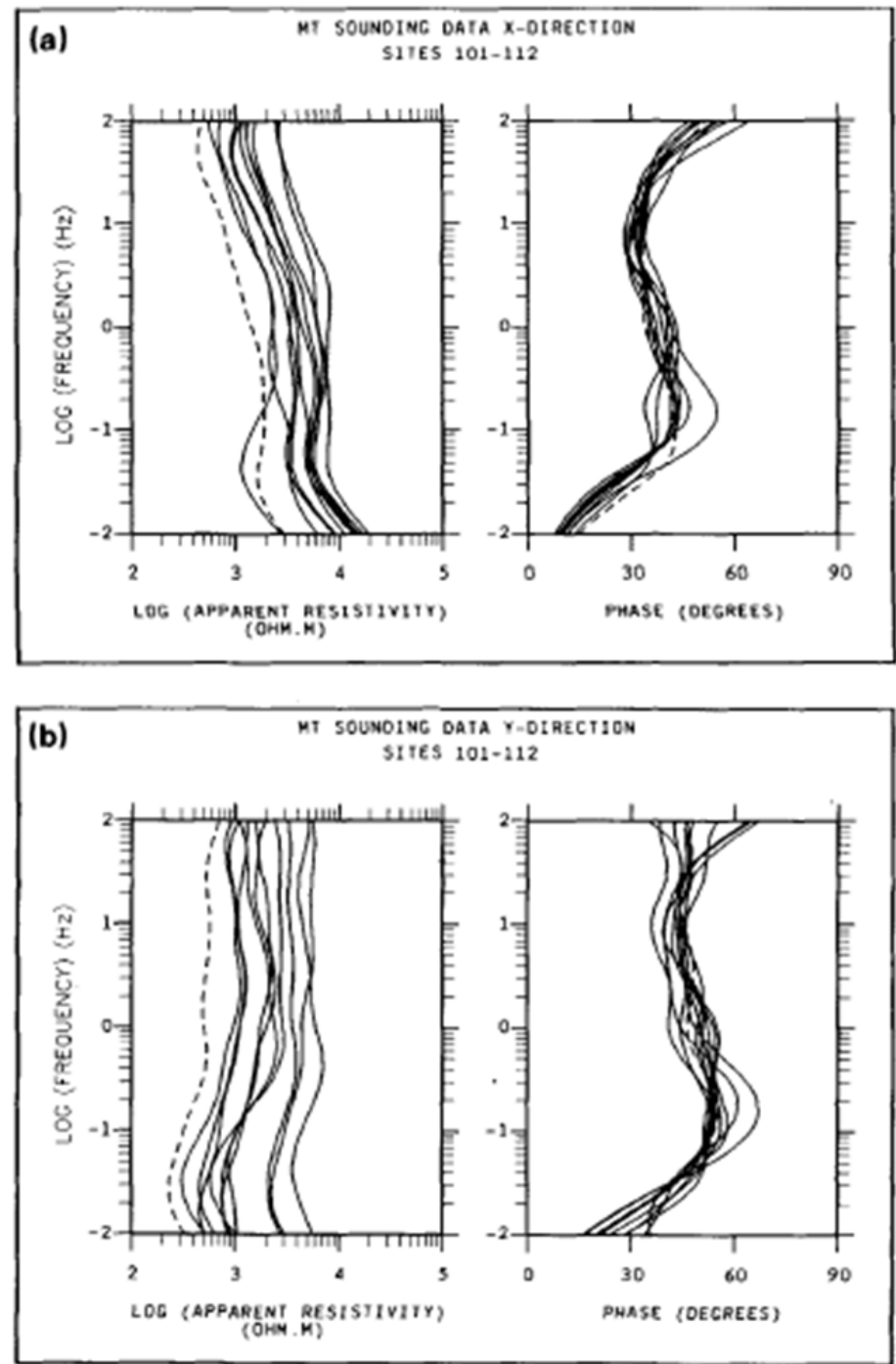

Figure 4. Complete set of sounding curves (11 sites on granite outcrop) in the measured off-diagonal components. Dash curves are from site 105. (a) $X$ component (north). (b) $Y$ component (east). 


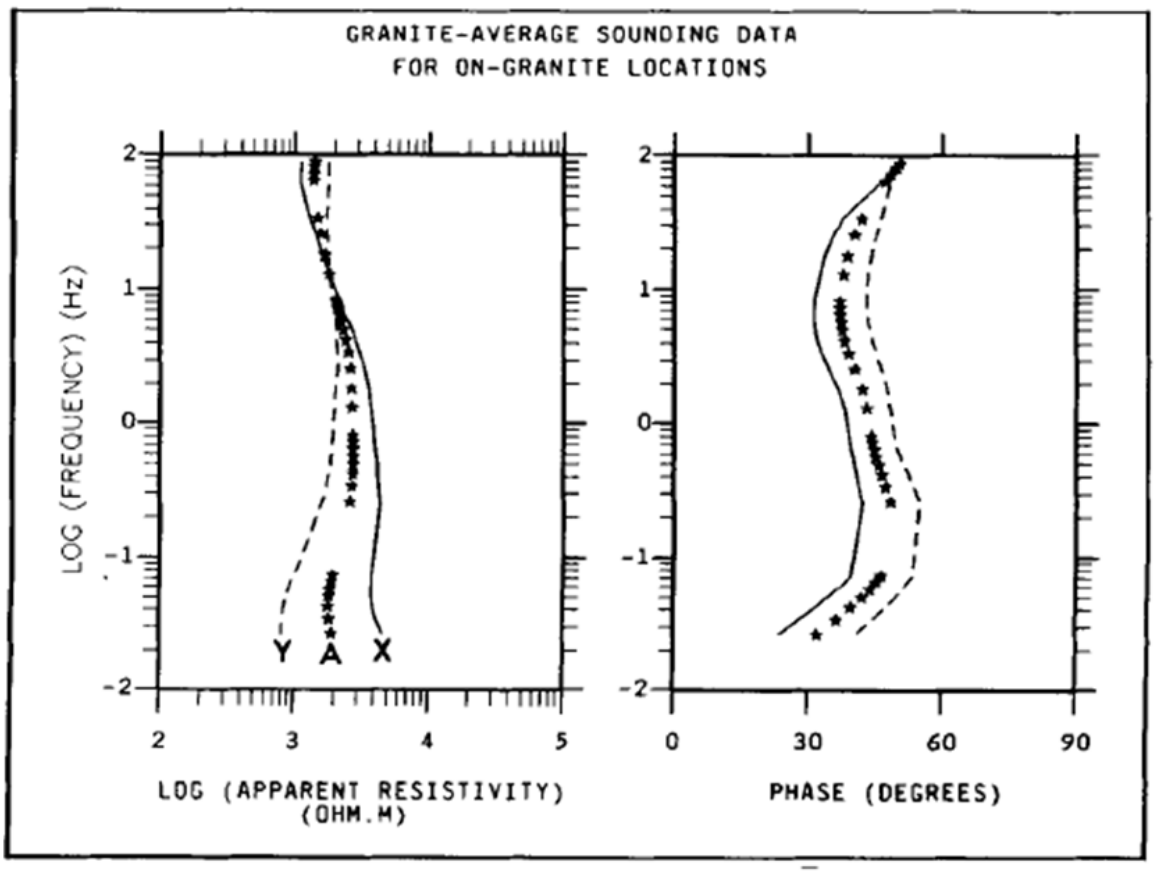

Figure 5. Granite-average sounding curves in the $X$ component (solid line), $Y$ component (dash line) and the determinant average sounding curve (solid symbols) obtained from the granite-average tensor. 


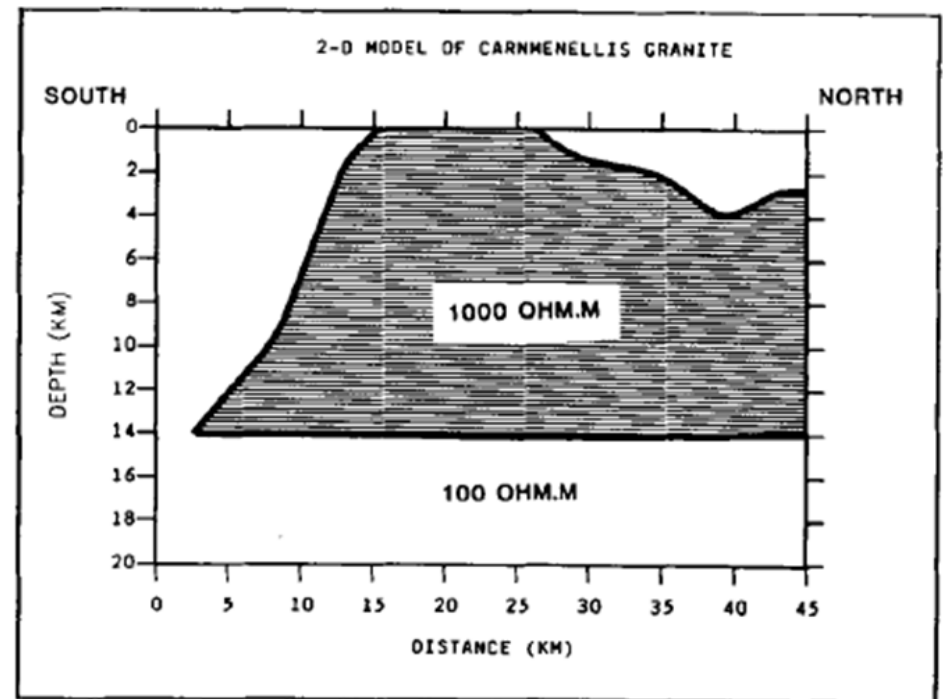

Figure 6. 2-D, north-south model cross-section showing the geometrical form of the granite defined by the 3-D regional gravity model and used to calculate the magnetotelluric sounding data across the granite outcrop. The outcrop distance is $13 \mathrm{~km}$. Only the central non-uniform section of the model is displayed. The actual numerical model extends several hundred kilometres beyond the boundaries shown. 


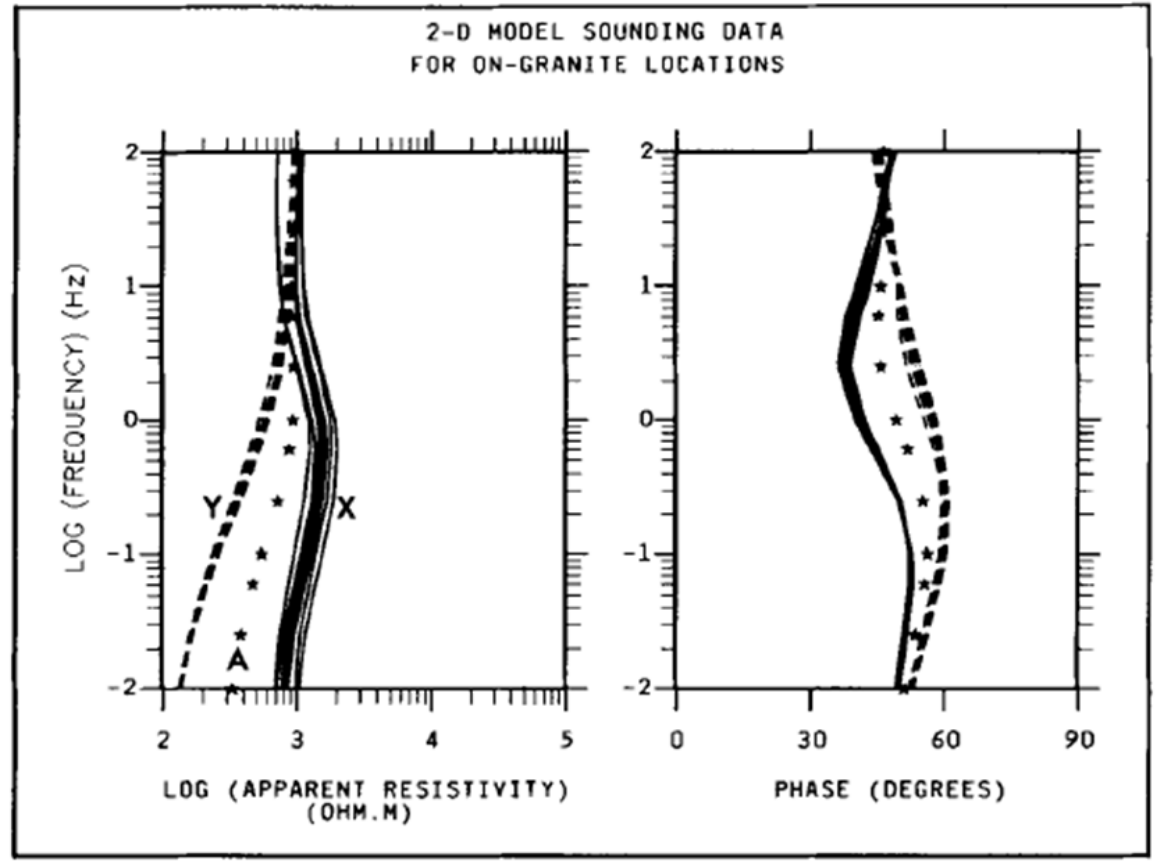

Figure 7. 2-D model sounding curves obtained at the 11 on-granite model locations in the $X$ component (solid lines), $Y$ component (dash lines) together with the determinant average sounding curve (solid symbols) obtained from the model granite-average tensor. 

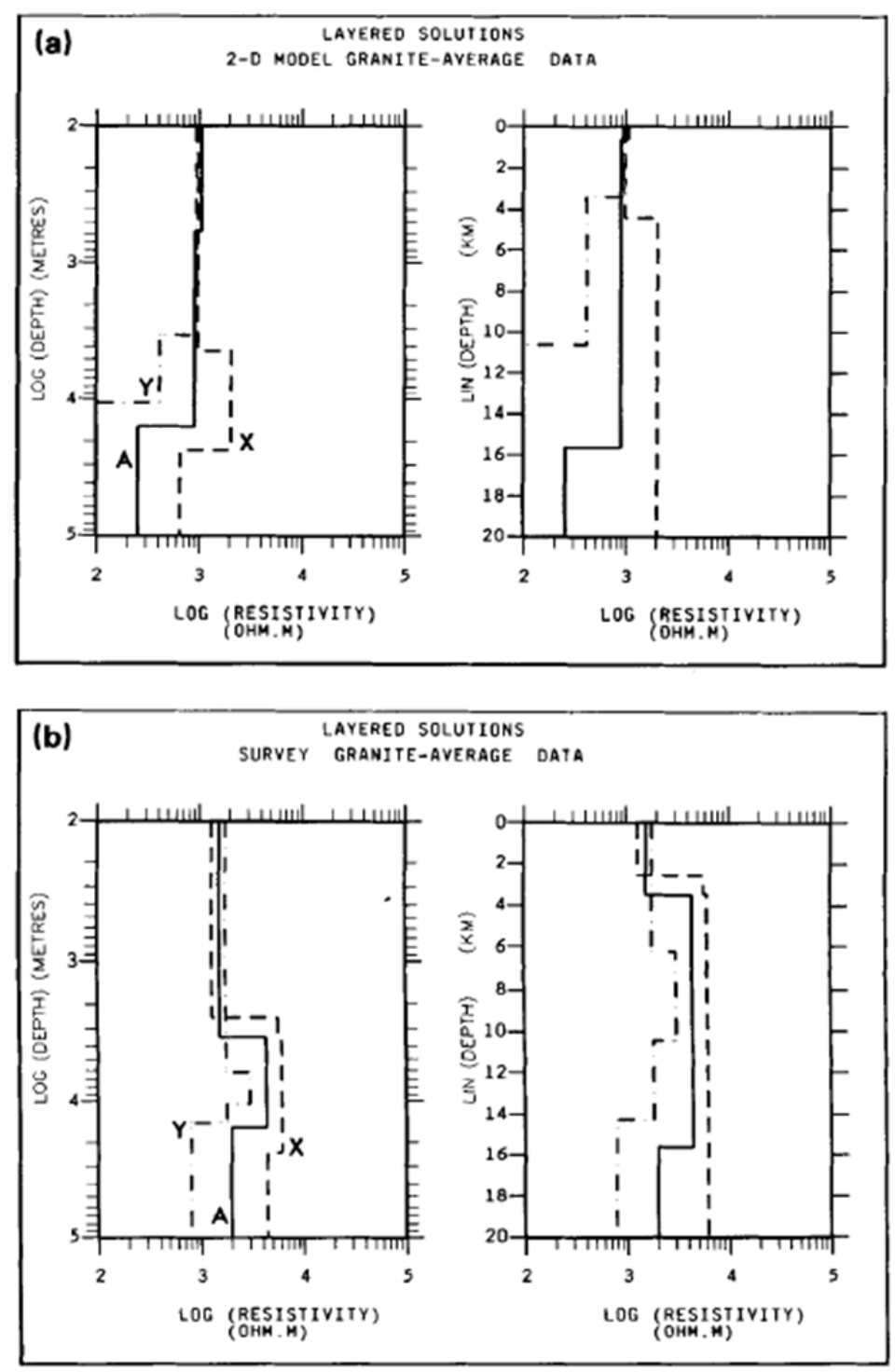

Figure 8. I-D layered inversion results for the $X$ component (dash line), $Y$ component (dot-dash line) and determinant average (solid line, A). Results shown in both logarithmic and linear depth domains. (a) 2-D model granite-average data. (b) Survey granite average data. 


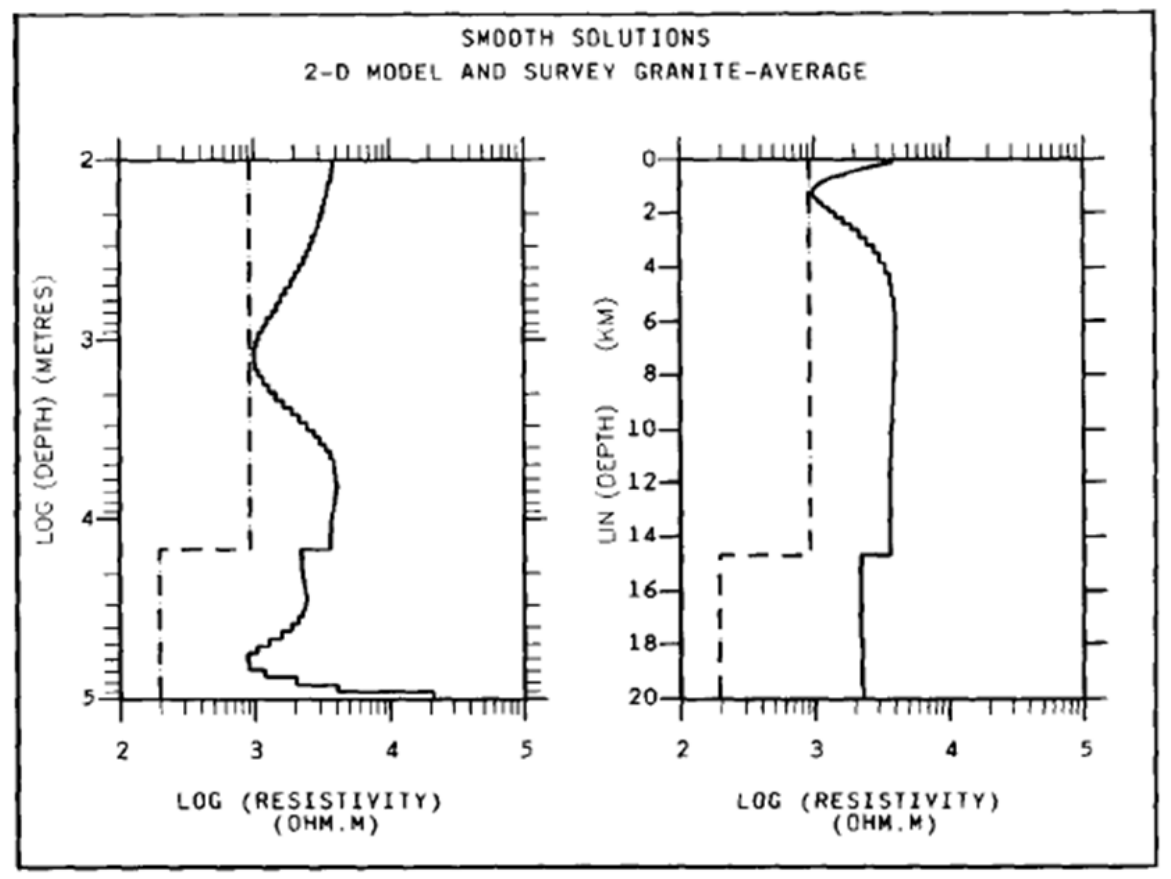

Figure 9. 1-D smooth inversion results for the determinant average sounding data. Results shown in both logarithmic and linear depth domains. Result for the 2-D model data is the dash line, result for the survey data is the solid line. The depth of the discontinuity at $14.6 \mathrm{~km}$ is predetermined but the resistivity contrast is not. 
TEMPERATURE ( $\times 100$ DEG $\mathrm{C})$

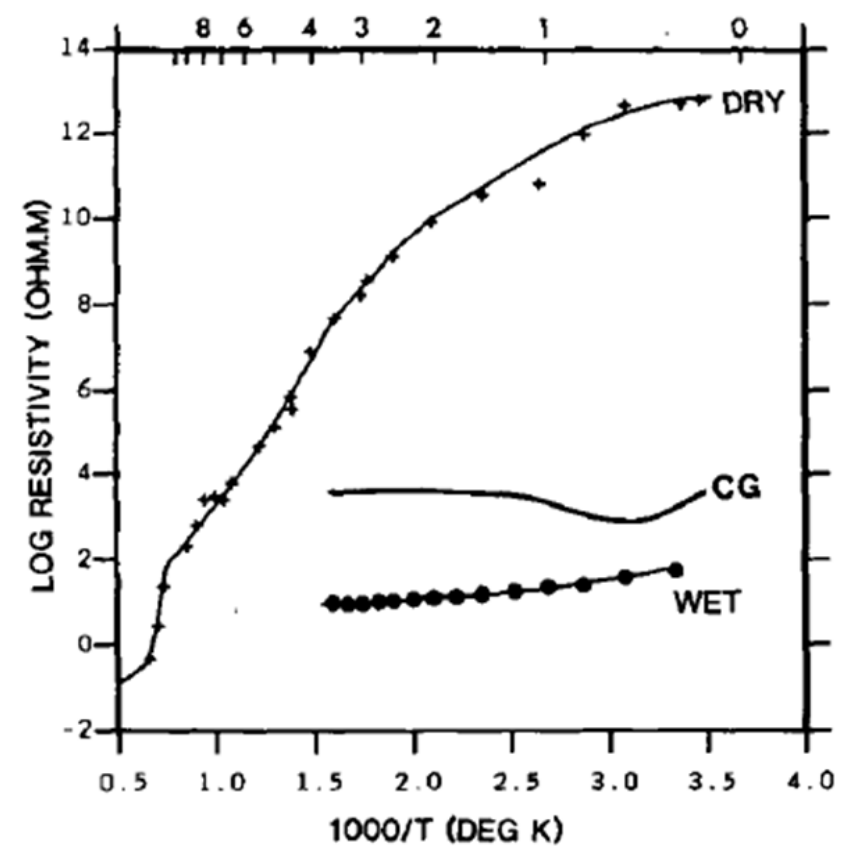

Figure 10. Summary of the laboratory data on the variation of resistivity with temperature for wet and dry granite (after Olhoeft 1981). Crosses (dry curve) are vacuum dry $\left(10^{-11} \mathrm{MPa}\right)$ Westerly granite. Closed circles (wet curve) are 0.4 molar $\mathrm{NaCl}$ solution-saturated Westerly granite. The resistivity curve for the Carnmenellis granite (CG) is also shown. 


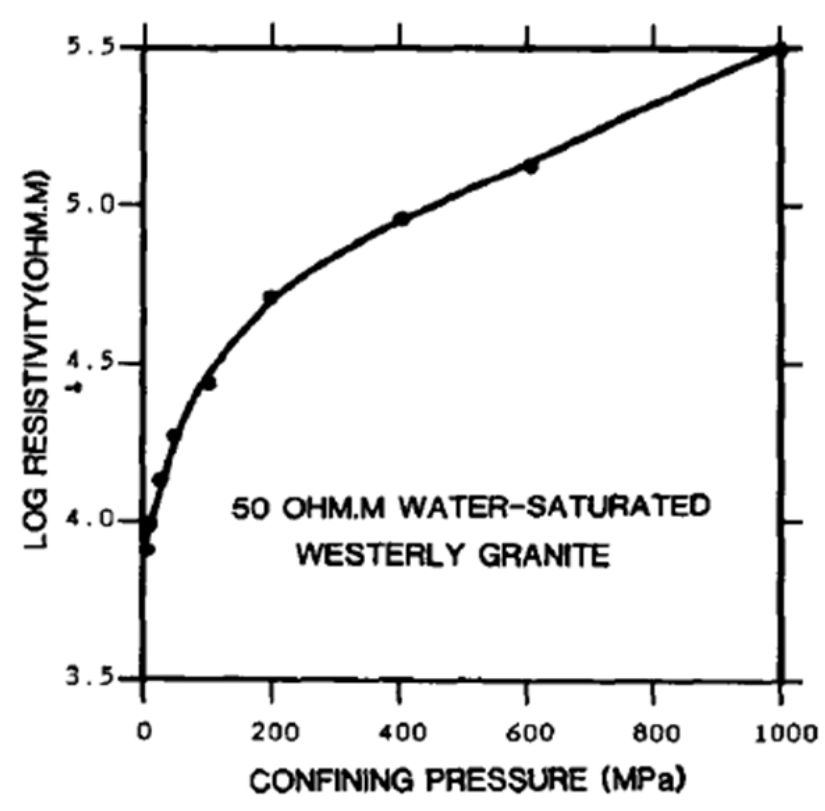

Figure 11. The effect of confining pressure on water-saturated Westerly granite (after Brace \& Orange 1968 and Olhoeft 1981). The curve is typical of all fluid-saturated crystalline rocks. 